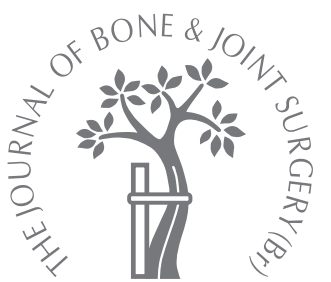

— CASE REPORT

\title{
Compartment syndrome following ankle sprain
}

\author{
N. J. Ward, \\ G. P. Wilde, \\ W. F. M. Jackson, \\ N. Walker
}

From John Radcliffe Hospital, Oxford, England
N. J. Ward, MRCS, SpR Orthopaedics

Wycombe General Hospital, Queen Alexandra Road, High Wycombe, Buckinghamshire HP11 2TT, UK.

G. P. Wilde, FRCS, Consultant Trauma \& Orthopaedic Surgeon

W. F. M. Jackson, FRCS(Trauma \& Orthopaedics), SpR Orthopaedics

Trauma Unit, John Radcliffe

Hospital, Headley Way, Headington, Oxford, OX3 9DU, UK.

N. Walker, MRCS, Senior House Officer in Trauma and Orthopaedics

Queen Alexandra Hospital, Southwick Hill Road, Cosham, Portsmouth PO6 3LY, UK.

Correspondence should be sent to $\mathrm{Mr}$ N. J. Ward; e-mail: nickjward72@hotmail.com

(C)2007 British Editorial Society of Bone and Joint Surgery doi:10.1302/0301-620X.89B7 $18906 \$ 2.00$

J Bone Joint Surg [Br] 2007;89-B:953-5.

Received 14 November 2006; Accepted after revision 19 February 2007

\begin{abstract}
Injury to the perforating branch of the peroneal artery has not been reported previously as a cause of acute compartment syndrome following soft-tissue injury to the ankle. We describe the case of a 23-year-old male who sustained such an injury resulting in an acute compartment syndrome. In a review of the literature, we could find only five previous cases, all of which gave rise to a false aneurysm which was detected after the acute event.
\end{abstract}

\section{Case report}

A 23-year-old soldier suffered an inversion sprain of the left ankle while playing basketball. The injury occurred when he landed with the foot plantar-flexed after jumping for the ball. He was unable to bear weight, and attended the Accident and Emergency department. Examination revealed tenderness around the insertion of the anterior talofibular ligament, and mild swelling of the anterolateral aspect of the ankle. The dorsalis pedis and posterior tibial pulses were both present. Radiographs of the ankle were normal. An acute sprain of the lateral ligaments was diagnosed and he was discharged with analgesics and advice on rehabilitation.

Approximately four hours later he returned with an increase in pain which was not relieved by simple analgesics. He was prescribed opioid analgesics and admitted for observation. When reviewed in the morning he was still in considerable discomfort and an orthopaedic opinion was sought.

There was a tense swelling of the anterolateral distal third of the leg with severe pain in the anterior compartment on passive stretching of the toes, an altered sensation in the distribution of the superficial peroneal nerve, and palpable dorsalis pedis and posterior tibial pulses. His pain was not controlled by opioid analgesics. The calf and lateral compartments were soft and free from pain. A clinical diagnosis of anterior compartment syndrome was made and urgent fasciotomy undertaken.

An incision was made directly over the tense swelling and a haematoma of approximately $30 \mathrm{ml}$ was found. The perforating branch of the peroneal artery had been avulsed and was actively bleeding. The artery was tied off and the haematoma evacuated. The more proximal musculature appeared healthy, with a good colour and contractility. The anterior talofibular ligament and the anterior capsule of the ankle joint were torn and were approximated with vicryl sutures. The wound was left open and the limb placed in a below-knee plaster slab. Post-operatively the pain was markedly reduced and passive stretching of the toes was unpainful. After 24 hours the ankle was immobilised in a removable backslab following closure of the wound. He was discharged in this plaster and referred to physiotherapy for early mobilisation and ankle exercises. The wound was formally closed at 48 hours when there remained some altered sensation over the dorsum of the foot with normal power in the toe extensors and extensor hallucis longus. At follow-up six weeks later the wound was well healed; there was normal sensation and full power in the toe and ankle extensors. The patient had returned to sporting activities.

\section{Discussion}

In 1955 Scott $^{1}$ described a case of traumatic aneurysm following injury to the perforating branch of the peroneal artery after a posterolateral approach to the distal tibia. We have only been able to find five subsequent descriptions of ankle sprain associated with injury to the peroneal artery or one of its branches. ${ }^{2-6}$ All these cases resulted in the formation of a false aneurysm which was diagnosed between five days and eight weeks after the injury. We believe this is the first reported case of an acute compartment syndrome related to rupture of the perforating peroneal artery after an ankle 
sprain. Maguire et $\mathrm{al}^{2}$ described a patient with an inversion injury who presented at five days with pain, and, on aspiration of an anterolateral haematoma, it was found to be pulsatile. An arteriogram confirmed a false aneurysm of the perforating peroneal artery which was subsequently excised and the artery repaired.

Four weeks after an ankle sprain Rainey et $\mathrm{al}^{3}$ also aspirated an anterolateral haematoma that was causing a sural nerve neuropathy. This was subsequently found to be pulsatile. Arteriography confirmed an aneurysm and the artery was explored and tied off. Rians et $\mathrm{al}^{4}$ described a patient with a 'goose-egg' swelling around the lateral malleolus three weeks after an inversion injury of the ankle. At eight weeks the swelling was pulsatile and arteriography showed a false aneurysm of the perforating peroneal artery, which was successfully treated by embolisation.

Marks et $\mathrm{al}^{5}$ described an aneurysm of the lateral malleolar branch of the peroneal artery after an inversion injury of the ankle. This had eroded through the soft tissues and formed an ulcer just anterior to the lateral malleolus. Thrombosis by external compression under Doppler guidance was unsuccessful, and so the aneurysm was excised and the artery tied off. Bandy et $\mathrm{al}^{6}$ described a false aneurysm of the anterior branch of the peroneal artery which was diagnosed after aspiration of the pulsatile swelling and a subsequent arteriogram 26 days after injury. It was successfully treated by embolisation.

Despite the relatively late presentation all the above cases made a complete recovery. While the aneurysms were symptomatic it seems unlikely that they were associated with a compartment syndrome. In our case we observed complete rupture of the artery, which was still actively bleeding at exploration and the clinical findings were highly suggestive of a compartment syndrome.

The perforating branch of the peroneal artery arises within flexor hallucis longus and passes through the interosseous membrane approximately $3 \mathrm{~cm}$ to $4 \mathrm{~cm}$ above the distal aspect of the tibia. Because of the secure attachment of the artery as it passes through the interosseous membrane and its close proximity to the head of the talus, it is susceptible to stresses in plantar flexion and inversion of the foot. ${ }^{2}$ Such forces may cause partial disruption, resulting in a false aneursym, or a complete rupture.

Maguire et $\mathrm{al}^{2}$ reported a vascular anomaly in $3.5 \%$ of the population causing attenuation of the anterior tibial artery, with the perforating peroneal artery continuing as the dorsalis pedis artery. This results in the course of the artery being more medial and in closer approximation to the head of the talus so that it is more likely to be injured during an inversion-plantar-flexion movement. We did not perform an arteriogram on our patient, but this anomaly was noted in the cases of Maguire et al, ${ }^{2}$ Rainey et $\mathrm{al}^{3}$ and Rians et al. ${ }^{4}$

We found 11 reports in the literature where a compartment syndrome had occurred following an apparently single soft-tissue injury of the ankle. Two had resulted from an arterial injury, and both caused a compartment syndrome in the foot. ${ }^{7,8}$

Apart from Creighton, Kinder and Bach, ${ }^{9}$ the remaining cases of compartment syndrome following an ankle sprain were a result of a rupture of the peroneus longus muscle. ${ }^{10-16}$ Creighton et $\mathrm{al}^{9}$ described a 17 -year-old who sustained an inversion injury of the ankle. The following day there were signs of an acute anterior and lateral compartment syndrome, and he underwent fasciotomy. A haematoma was released from the lateral compartment, but no venous, arterial or muscle injury was found. The cases of peroneus longus rupture followed traumatic contact injuries sustained during sport and more innocuous, non-traumatic sprains. They presented as early as two hours after injury, and treatment in the initially unrecognised cases ${ }^{15,16}$ was as late as ten days after the presentation. Arciero et al, ${ }^{10}$ Davies $^{12}$ and Williams et $\mathrm{al}^{16}$ all reported residual deficits following surgery, varying from hypoaesthesia to foot drop requiring tendon transfer. The common pathophysiology appears to be one of muscle injury with haemorrhage and oedema, resulting in a rise in intracompartmental pressure.

A compartment syndrome may develop after an ankle sprain and it is usually a result of a tear of the peroneus longus muscle or of an injury to the perforating branch of the peroneal artery.

A vascular anomaly, said to be present in $3.5 \%$ of the population, may make the perforating branch of the peroneal artery more susceptible to injury during an inversion sprain.

No benefits in any form have been received or will be received from a commercial party related directly or indirectly to the subject of this article.

\section{References}

1. Scott JHS. Traumatic aneurysm of the peroneal artery. J Bone Joint Surg [Br] 1955;37-B:438-9.

2. Maguire DW, Huffer MD, Ahlstrand RA, Crummy AB Jr. Traumatic aneurysm of the perforating peroneal artery: arterial bleeding. J Bone Joint Surg [Am] 1972;54A:409-12.

3. Rainey RK, Anderson C, Sehorn S, Sears S. Traumatic false aneurysm of the ankle. Clin Orthop 1983;176:163-5.

4. Rians CB, Bishop AF, Montgomery CE, Cahill BR. False aneurysm of the perforating peroneal artery: a complications of lateral ankle sprain. J Bone Joint Surg [Am] 1990;72-A:773-5

5. Marks RM, Stroud CC, Walsh D. Pseudoaneurysm of the lateral malleolar artery after an ankle sprain: case report and review of the literature. Foot Ankle Int 1990;20:741-3.

6. Bandy WD, Strong L, Roberts T, Dyer R. False aneurysm: a complication following an inversion ankle sprain. J Orthop Sports Phys Ther 1996;23:272-9.

7. Kym MR, Worsing RA. Compartment syndrome in the foot after an inversion injury to the ankle: a case report. J Bone Joint Surg [Am]1990;72-A:138-9.

8. Dhawan A, Doukas WC. Acute compartment syndrome of the foot following an inversion injury of the ankle with disruption of the anterior tibial artery: a case report. J Bone Joint Surg [Am] 2003;85-A:528-32.

9. Creighton RA, Kinder J, Bach BR. Compartment syndrome following recurrent ankle inversion injury. Orthopedics 2005;28:703-5.

10. Arciero RA, Shishido NS, Parr TJ. Acute anterolateral compartment syndrome secondary to rupture of the peroneus longus muscle. Am J Sports Med 1984;12:3667

11. Gabisan GG, Gentile DR. Acute peroneal compartment syndrome following ankle inversion injury: a case report. Am J Sports Med 2004;32:1059-61.

12. Davies JA. Peroneal compartment syndrome secondary to supture of the peroneus Iongus: a case report. J Bone Joint Surg [Am] 1979;61-A:783-4. 
13. Moyer RA, Boden BP, Marchetto PA, Kleinbart F, Kelly JD 4th. Acute compartment syndrome of the lower extremity secondary to noncontact injury. Foot Ankle 1993;14:534-7.

14. Power RA, Greengross P. Acute lower leg compartment syndrome. Br J Sports Med 1991:25:218-20.
15. Goodman MJ. Isolated lateral-compartment sydrome: report of a case. J Bone Joint Surg [Am] 1980;62-A:834.

16. Williams P, Shenolikar A, Roberts RC, Davies RM. Acute non-traumatic compartment syndrome related to soft tissue injury. Injury 1996;27:507-8. 